\title{
ALKALI-ACTIVATED BINDERS PRODUCED FROM PETROCHEMICAL FLUID CATALYTIC CRACKING CATALYST WASTE
}

\author{
Carla Costa $^{1}$, Cátia Ferreira ${ }^{2}$, M. Filipa Ribeiro ${ }^{3}$, Auguste Fernandes ${ }^{4}$ \\ ${ }^{1}$ Area Departamental de Engenharia Civil, Instituto Superior de Engenharia de Lisboa, Lisboa, Portugal \\ ${ }^{2}$ Area Departamental de Engenharia Civil, Instituto Superior de Engenharia de Lisboa, Lisboa, Portugal \\ ${ }^{3}$ Instituto de Biotecnologia e Bioengenharia, Centro de Engenharia Biológica e Química, Instituto Superior Técnico, \\ Universidade de Lisboa, Lisboa, Portugal \\ ${ }^{4}$ Instituto de Biotecnologia e Bioengenharia, Centro de Engenharia Biológica e Química, Instituto Superior Técnico, \\ Universidade de Lisboa, Lisboa, Portugal
}

\begin{abstract}
This paper describes research on the viability of producing alkali activated binders using the aluminosilicate catalyst waste generated by the fluid catalytic cracking (wFCC) unit in the Portuguese oil refinery company - as precursor. For this purpose, alkali-activated wFCC catalyst based mortars and cement pastes were produced. Tests were carried out to evaluate the effect of initial solids composition (wFCC catalyst/Ca(OH $)_{2}$ ratio) on mortars workability or mechanical strength. The mineralogy and microstructure of the hardened alkali activated wFCC catalyst pastes were studied by means of Fourier transform infrared spectroscopy (FTIR) and X-ray diffraction (XRD).

The results obtained at macroscale showed that the content of $\mathrm{Ca}(\mathrm{OH})_{2}$ incorporated in the binder has a significant effect on compressive strength of hardened mortars. At microscale, FTIR and XRD results confirmed the occurrence of alkali-activation of the wFCC catalyst which leads to the formation of distinctive amorphous and crystalline products. Moreover, the obtained results also suggest that initial solids composition influences the alkali-activation reaction kinetics and mechanism.
\end{abstract}

Keywords: Alkali-activated binders, waste FCC catalyst, Mechanical strength, FTIR, XRD

\section{INTRODUCTION}

Alkali-activated (AA) aluminosilicate materials constitute a class of hydraulics binders which binder's ability is due to hydrated aluminosilicates compounds - geopolymers - with chemical formula $\mathrm{M} n\left\{\left(\mathrm{SiO}_{2}\right)_{\mathrm{z}} \cdot \mathrm{AlO}_{2}\right\} n$. $\mathrm{wH}_{2} \mathrm{O}$, wherein $\mathrm{M}$, is a cation usually $\mathrm{Na}^{+}, \mathrm{K}^{+}$or $\mathrm{Ca}^{2+} ; n$, is the polymerization degree; w, hydration degree; e $\mathrm{z}$, is 1,2 or 3 [1].

Alkali-activation reaction mechanism or geopolymerization includes the dissolution of the precursor aluminosilicate by an activator alkaline solution (typically at a temperature slightly higher than room temperature) producing a complex mixture of silicate, aluminate and aluminosilicate species. These species, present in a supersatured solution, co-polymerize to form semi-crystalline three-dimensional aluminosilicate materials [2, 3, 4].

Often AA binders reveal technological advantages over ordinary Portland cements such as better mechanical resistance [3, 5], greater durability $[3,6]$ and refractory properties [4]. In addition, the use of these binders has environmental benefits because the replacement of ordinary Portland cements significantly reduces the consumption of non-renewable raw materials and energy as well as concurs to $\mathrm{CO}_{2}$ emissions mitigation. Moreover, if the $\mathrm{AA}$ aluminosilicate precursor is a waste from other industry, geopolymers production also diverts the wastes from being disposed of in landfills.

For these reasons, geopolymerization is an emerging research area focused on both fundamental and applied studies. Several different precursor materials have been activated such as metakaolin $[7,8,9,10,11]$, fly ashes [12, $13,14,15]$, blast-furnace slag $[9,11,16]$, natural zeolites [6], tungsten mine waste [17], red clay brick wastes [18] and waste from oil-industry [19, 20, 21].

In this context, this paper presents results of an on-going research on the viability of producing AA binders using, as precursor, the waste catalyst generated in the fluid catalytic cracking (wFCC) unit by the Portuguese oil refinery company, PETROGAL S.A.. This waste is an aluminosilicate constituted by a zeolite with faujasite-type structure $(5-40 \%)$ incorporated in a matrix, essentially of alumina and other amorphous aluminosilicates [22, 23]. This work evaluates the effect of $\mathrm{wFCC} / \mathrm{Ca}(\mathrm{OH})_{2}$ ratio on mortars workability and mechanical strength as well as analyses the formed products by Fourier transform infrared spectroscopy (FTIR) and X-Ray diffraction (XRD). 


\section{EXPERIMENTAL PROGRAM}

\subsection{Materials}

The raw materials used were: waste FCC catalyst (wFCC), generated by Portuguese refinery company PETROGAL S.A.; two different natural siliceous sands, one coarser designated as Sand 0/4 (density 2.62, fineness modulus of 5.48 , water absorption of $0.5 \%$ ) and one finer designated as Sand 0/2 (density 2.94, fineness modulus of 3.94, water absorption of $0.3 \%$ ); calcium hydroxide $\left(\mathrm{Ca}(\mathrm{OH})_{2}\right)$ (powder, purity > 95\% by Panreac); sodium hydroxide $(\mathrm{NaOH})$ (pellets, purity > $99.9 \%$ by Normapur); and deionized water.

The chemical composition of wFCC catalyst (Table 1) was obtained by X-ray fluorescence spectrometry (using a PANalytical model Axios equipment) as well as by loss on ignition (LOI) following European standard EN 196-2. The total $\mathrm{SiO}_{2}$ and $\mathrm{Al}_{2} \mathrm{O}_{3}$ content in the waste catalyst approximately $92 \% \mathrm{w} / \mathrm{w}$ - makes this material a protential precursor in the production of AA binders [5, 22].

Table 1: Chemical composition of wFCC catalyst

\begin{tabular}{|l|l|}
\hline Chemical composition (\% w/w) & wFCC catalyst \\
\hline $\mathrm{SiO}_{2}$ & 39.59 \\
\hline $\mathrm{Al}_{2} \mathrm{O}_{3}$ & 52.81 \\
\hline $\mathrm{Fe}_{2} \mathrm{O}_{3}$ & 0.55 \\
\hline $\mathrm{CaO}$ & 0.09 \\
\hline $\mathrm{MgO}$ & 0.19 \\
\hline $\mathrm{SO}_{3}$ & 0.23 \\
\hline $\mathrm{K}_{2} \mathrm{O}$ & 0.04 \\
\hline $\mathrm{Na}_{2} \mathrm{O}$ & 0.68 \\
\hline $\mathrm{Ti}_{2} \mathrm{O}_{3}$ & 0.82 \\
\hline $\mathrm{P}_{2} \mathrm{O}_{5}$ & 0.06 \\
\hline Loss by ignition (LOI) & 1.49 \\
\hline TOTAL & $\mathbf{9 9 . 5 6}$ \\
\hline
\end{tabular}

Table 2 lists the results of the physical characterization of the wFCC catalyst. The specific density was determined by helium pycnometry using an AccuPyc 1330 instrument from Micromeritics, specific surface area was determined by nitrogen sorption isotherm at $77 \mathrm{~K}$ using a Micromeritics ASAP 2000 apparatus. The particle size distribution (PSD) was obtained by laser diffraction using a PSA 1064 CILAS equipment [22]. PSD result was used to estimate the mean particle size of wFCC catalyst particles as well as $d_{50}$ and $d_{90}$ values.

Table 2: Physical properties of wFCC catalyst

\begin{tabular}{|l|l|}
\hline Specific gravity $\left(\mathrm{g} \cdot \mathrm{cm}^{-3}\right)$ & 2.71 \\
\hline Specific surface area $\left(\mathrm{m}^{2} \cdot \mathrm{g}^{-1}\right)$ & 150.07 \\
\hline Mean particle size $(\mu \mathrm{m})$ & 83.10 \\
\hline $\mathrm{d}_{50}(\mu \mathrm{m})^{1}$ & 80.00 \\
\hline $\mathrm{d}_{90}(\mu \mathrm{m})^{1}$ & 124.30 \\
\hline $\mathrm{d}_{50}$ and $\mathrm{d}_{90}-50 \%$ and 90 \% (v/v) of particles,
\end{tabular}
respectively, have diameters smaller than the presented value.
Both sands - Sand 0/4 and Sand 0/2 - particle size distributions were obtained by using sieving method following European standard EN 933-2. Fig. 1 shows particle size distribution curves for both sands as well as for sand mixture containing $40 \%$ of Sand $0 / 2$ e $60 \%$ of Sand 0/4 (mass percentages). The mixture proportion of the two sands was determined experimentally in order to obtain maximum bulk densities.

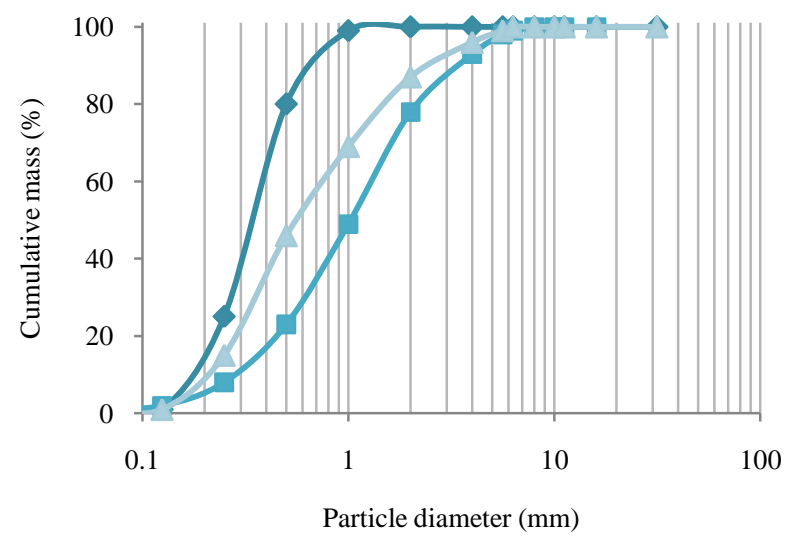

Fig. 1: Cumulative particle size distribution of the sands ( $\bullet$ - Sand 0/2; ( $\mathbf{\square})$ - Sand 0/4; ( $\boldsymbol{\Delta})$ - Mixture of sands used $(40 \%(w / w)$ Sand 0/2 +60\% (w/w) Sand 0/4).

\subsection{Mortars: Preparation and Tests}

Mortars were prepared using activation solution $(\mathrm{NaOH} 5$ $\mathrm{M}$ ), binder (b) and sand (s), in a mass ratio, $\mathrm{NAOH} / \mathrm{b} / \mathrm{s}$ of $1 / 1 / 2.5$. Binders used consisted in different proportions blends of wFCC catalyst with $\mathrm{Ca}(\mathrm{OH})_{2}$ (Table 3 ).

Table 3: Notation adopted for binders used.

\begin{tabular}{|l|l|l|}
\hline \multirow{2}{*}{ Notation } & \multicolumn{2}{|l|}{ Binder blends proportions $(\% \mathrm{w} / \mathrm{w})$} \\
\cline { 2 - 3 } & wFCC & $\mathrm{Ca}(\mathrm{OH})_{2}$ \\
\hline 90wFCC_10CH & 90 & 10 \\
\hline 85wFCC_15CH & 85 & 15 \\
\hline 80wFCC_20CH & 80 & 20 \\
\hline 75wFCC_25CH & 75 & 25 \\
\hline 70wFCC_30CH & 70 & 30 \\
\hline 65wFCC_35CH & 65 & 35 \\
\hline 60wFCC_40CH & 60 & 40 \\
\hline
\end{tabular}

Mortars mixing procedure was performed in the accordance with the scheme presented in the Fig. 2.

Consistency of fresh mortars was evaluated, immediately after mixing, by flow table test as prescribed in European standard EN 1015-3. 


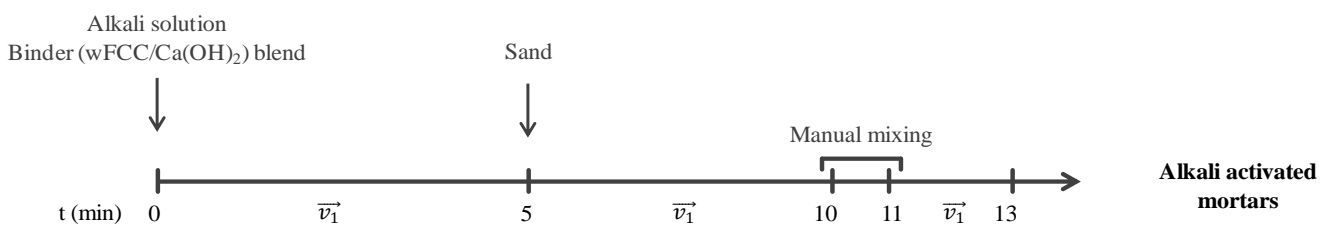

Fig. 2: Schematic representation of mortars mixing procedure (t: time in minutes; $\overrightarrow{\boldsymbol{v}_{\mathbf{1}}}$ : low speed, $140 \pm 5$ rotations $\left.\cdot \mathrm{min}^{-1}\right)$.

After the flow test, mortars were placed in prismatic steel molds 4x4x16 cm and compacted following European standard EN 196-1. Thereafter, the molds were placed in hermetically sealed bags and cured in a wet cabinet (Matest, model E138) at $55 \pm 5^{\circ} \mathrm{C}$ and $\mathrm{RH} \geq 95 \%$. Compressive strength of mortars was obtained by using a universal testing machine, according again to EN 196-1 standard at 1, 2, 7 and 28 days of activation reaction. Compressive strength results were calculated as a mean of six values.

\subsection{Reaction Products Analysis}

Products of $w F C C / C a(O H)_{2}$ alkali-activated reactions were analyzed in pastes with the composition corresponding to the appropriate mortars (i.e., exactly the same composition except for the sand). The pastes were also prepared using the same mixture procedure applied for mortars (Fig.2) without the step of adding sand. Reaction products were analysed by Fourier transform infrared spectroscopy (FTIR) and X-Ray diffraction (XRD).

Powder FTIR spectra were collected on a Nicolet Nexus FTIR spectrometer in the range of $4000-600 \mathrm{~cm}^{-1}$, with 64 scans at a resolution of $4 \mathrm{~cm}^{-1}$. Samples were prepared mixing the $\mathrm{AA}-\mathrm{wFCC} / \mathrm{Ca}(\mathrm{OH})_{2}$ pastes with $\mathrm{KBr}$ powder in a weight ratio paste/KBr of $1 / 100$ and pressing into pellets.

XRD diffractograms were obtained in a Bruker AXS D8 diffractometer with $\mathrm{Cu}-\mathrm{K} \alpha$ radiation $(40 \mathrm{~mA}, 40 \mathrm{kV}$ e $\lambda=$ $1.5406 \AA$ ) in the $2 \theta$ range $5-70^{\circ}$ with an increment of 0.05 measured at each $3 \mathrm{~s}$. Analyzed samples consisted in blends of the AA-wFCC/Ca(OH $)_{2}$ pastes with an internal standard $\mathrm{TiO}_{2}$-anatase (purity $>99 \%$ ) in a mass ratio paste/anatase of 1/9. Diffractograms were processed using AXS DiffracPlus EVA software by Bruker AXS based on normalization of maximum anatase main peak intensity and position at $2 \theta=$ $25.28^{\circ}$. Phases present were identified by comparison of obtained diffractograms with standard diffraction patterns of Powder Diffraction File ${ }^{\mathrm{TM}}$ (PDF-4) database offered by the International Centre for Diffraction Data (ICDD).

\section{RESULTS AND DISCUSSION}

Previous to the investigation described in this paper, the effect on mortars mechanical properties promoted by different binder compositions as well as different activation and cure conditions, were evaluated. The results of these tests showed that specimens without $\mathrm{Ca}(\mathrm{OH})_{2}$ in the binder composition and cured at room temperature do not harden. Moreover, concentration of $\mathrm{NaOH}$ solution of $5 \mathrm{M}$ leads to stronger mortars than if it is 10 or $16 \mathrm{M}$.

\subsection{Consistency of Mortars}

Fig. 3 presents the consistency results of AA-wFCC/Ca $(\mathrm{OH})_{2}$ mortars assessed through spread values on the flow table. The results show that by decreasing the wFCC catalyst content in the binder - from $w F C C / C a(O H)_{2}=90 / 10$ to $65 / 35$ - there is a steady increase in the spread value and, therefore, in the mortar fluidity (until a maximum of $205 \mathrm{~mm}$ for $\mathrm{wFCC} / \mathrm{Ca}(\mathrm{OH})_{2}=65 / 35$ mortar). However, there is an inversion in this trend for the $w F C C / C a(O H)_{2}=60 / 40$ mortar which presents the lowest fluidity value, although it exhibits the lowest wFCC content in the binder.

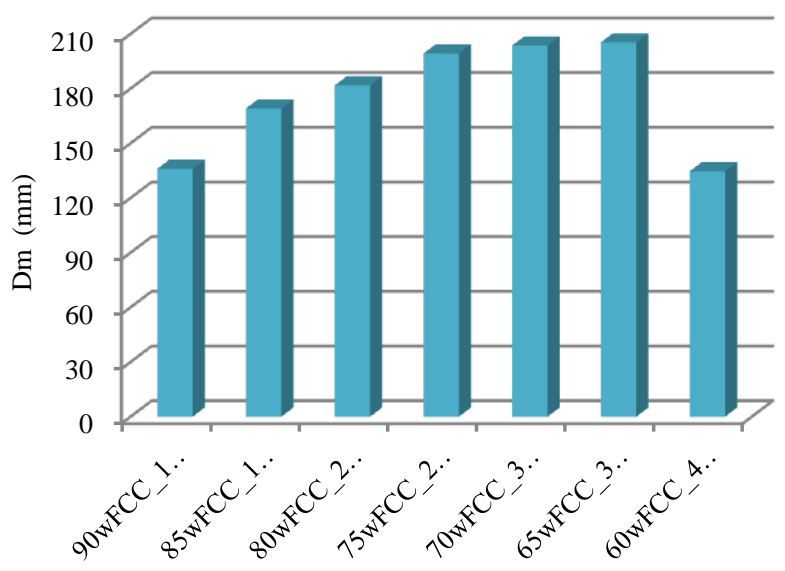

Fig. 3: Spread values on flow table test (mm) of alkaly-activated wFCC catalyst/Ca(OH $)_{2}$ mortars.

The reduction on the workability of the mortars with higher levels of wFCC catalyst incorporation could be attributable to the significant water absorption ability of the waste particles due to their huge specific surface area and water affinity (Table 2) [23]. However, further research is needed to be done in order to understand the inversion in fresh state fluidity trend revealed by $\mathrm{FCC} / \mathrm{Ca}(\mathrm{OH})_{2}=60 / 40$ mortar.

\subsection{Compressive strength}

Fig. 4 shows compressive strengths of AA-wFCC/Ca(OH $)_{2}$ mortars at 1, 2, 7 and 28 days of activation reaction. These results reveal that the $\mathrm{Ca}(\mathrm{OH})_{2}$ content in the binder significantly affects the mortars compressive strengths. Namely:

- on $1^{\text {st }}$ day of reaction the compressive strength increases with the $\mathrm{Ca}(\mathrm{OH})_{2}$ content in the binder composition, which could mean that this compound 
contributes to accelerate the wFCC catalyst alkali-activation reaction rate;

- $\quad$ from the $2^{\text {nd }}$ day of reaction, results show (i) a maximum in the AA mortars compressive strength for a given level of incorporation of $\mathrm{Ca}(\mathrm{OH})_{2}$ in the binder; and that (ii) as the reaction times increases the maximum strength value shifts towards lower content of $\mathrm{Ca}(\mathrm{OH})_{2}$ in the binder;

- mortars with incorporation of $\mathrm{Ca}(\mathrm{OH})_{2}$ up to $30 \%$ $\mathrm{w} / \mathrm{w}$ in the binder composition exhibit an increase in strength development during the first 28 days of reaction;

- mortars with $35 \%$ and $40 \%$ incorporation of $\mathrm{Ca}(\mathrm{OH})_{2}$ in the binder composition exhibit a strength reduction after a given reaction time.
Indeed, the strength of the $65 \mathrm{wFCC} \_35 \mathrm{CH}$ mortar increases up to 2 days of reaction and from this reaction time the strength decreases while the strength of the 60wFCC_40CH mortar decreases from the first reaction day.

The compressive strength reduction observed, after some reaction time, for the mortars prepared with both highest levels of $\mathrm{Ca}(\mathrm{OH})_{2}$ seems actually to be related with an acceleration promoted by $\mathrm{Ca}(\mathrm{OH})_{2}$ in the AA reaction of wFCC catalyst which leads to modifications in binders microstructure, as it is also corroborated by FTIR (section 3.3) and XRD (section 3.4) results.

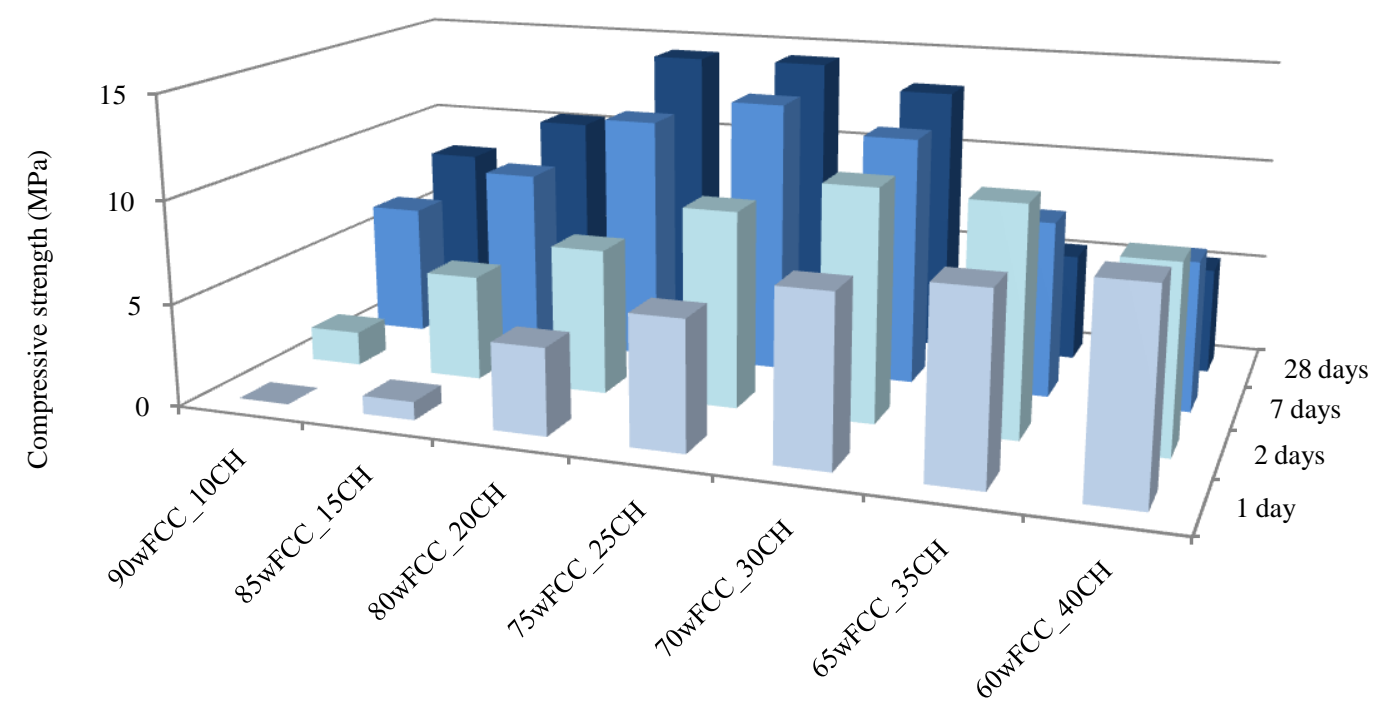

Fig. 4: Compressive strength of alkali-activated wFCC catalyst/Ca(OH) $)_{2}$ mortars, at 1, 2, 7 and 28 days of reaction.

Other research studies have also shown that $\mathrm{Ca}(\mathrm{OH})_{2}$ incorporation in the binder affects strength development of AA mortars. However, different investigations reveal distinct effects. In fact whereas, for instance, the increase in the content of $\mathrm{Ca}(\mathrm{OH})_{2}$ in AA of a metakaolin leads to a decrease of mortars mechanical strength [8], its increasing presence in AA of natural zeolite clinoptilolite leads to an increase of the mortars strength [24], and there are others studies that revealed the existence of an optimum $\mathrm{Ca}(\mathrm{OH})_{2}$ content in alkali-activation of a tungsten mine waste and of a metakaolin to reach the maximum strength $[9,17]$.

\subsection{FTIR Analysis}

Fig. 5 shows the FTIR spectrum obtained with wFCC catalyst as well as selected FTIR spectra obtained with $\mathrm{AA}-\mathrm{wFCC} / \mathrm{Ca}(\mathrm{OH})_{2}$ pastes namely, with the 75wFCC_25CH and 60wFCC_40CH pastes. Table 4 lists the assignments of the bands present in the spectra. The reason to specifically present and discuss the AA reaction products of these two pastes in more detail lies on their quite distinct mechanical strength behavior (Fig. 4) which should be due to differences in their microstructure. In concrete, whereas compressive strength of $75 \mathrm{wFCC} 25 \mathrm{CH}$ mortar steadily increased with reaction time the compressive strength of 60wFCC_40CH mortar decreased from the first day of reaction. Furthermore, 75wFCC_25CH mortar reached the highest value of all the mortars tested.

Analysis of Fig. 5 and Table 4 reveal that the infrared spectrum of the wFCC catalyst presents the bands at $\sim 1205$ and $1078 \mathrm{~cm}^{-1}$ assigned to the asymmetric stretching vibrations of $\mathrm{T}-\mathrm{O}-\mathrm{T}$ bonds characteristics of its crystalline faujasite-type structure [20]. However, these bands are already absent in the AA-pastes after the first reaction day. The disappearance of these bands is attributed to the quick dissolution of the wFCC crystalline structure due to the strong basicity promoted both by $\mathrm{Ca}(\mathrm{OH})_{2}$ and the alkaline solution.

Moreover, the infrared spectra of AA-pastes reveal the appearance of a new band centered at $1000 \mathrm{~cm}^{-1}$ which represents the merging of the asymmetric stretching vibrations of both Al-O e Si-O. This band is considered to 
be a major fingerprint of geopolymers formation within the binder matrices [13]. However, the differences in the FTIR spectra profiles of:

- the different AA-pastes, for the same time reaction, indicate that the level of $\mathrm{Ca}(\mathrm{OH})_{2}$ incorporated in the binder, affects the reaction mechanism and, thus, the chemical composition of the hydrated aluminosilicate compounds that constitute the geopolymers;

- the same AA-pastes over reaction time indicate rearrangements in the geopolymers microstructure as the AA reaction proceeds.
In fact, considering only the region of FTIR spectra corresponding to geopolymers compounds $\left(\sim 1000 \mathrm{~cm}^{-1}\right)$, whereas in the spectrum of $75 \mathrm{wFCC} \_25 \mathrm{CH}$ paste it is difficult to distinguish any peaks (maybe due to the high degree of band overlap) the spectra of the $60 \mathrm{wFCC} \_40 \mathrm{CH}$ paste already present traces of peaks on first reaction day and they become more defined as the activation reaction proceeds. This fact may be indicate the existence of some local order that is more quickly achieved in the gel formed in $60 \mathrm{wFCC} \_40 \mathrm{CH}$ paste than in $75 \mathrm{wFCC} \_25 \mathrm{CH}$ paste and that it continues to increase over reaction time.

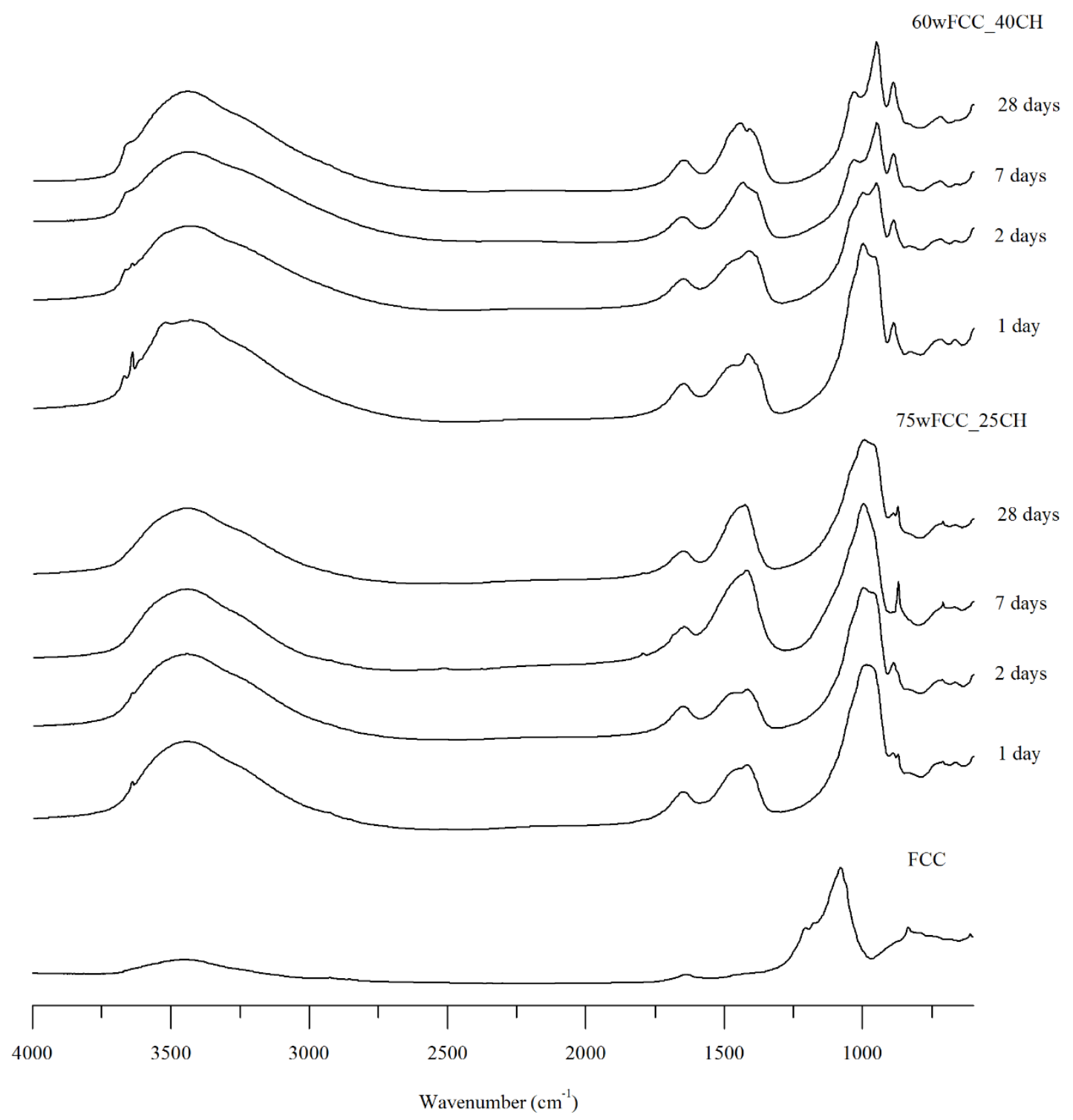

Fig. 5: FTIR spectra of wFCC catalyst as well as of $75 w F C C \_25 \mathrm{CH}$ and $60 w F C C \_40 \mathrm{CH}$ pastes at $1,2,7$ and 28 days of alkali-activation reaction.

Table 4: Assignment of the bands present in FTIR spectra [13, 16, 20, 25, 26, 27, 28].

\begin{tabular}{|l|l|}
\hline Frequency $\left(\mathbf{c m}^{-1}\right)$ & Band assignment \\
\hline 3700 to 3000 & $\begin{array}{l}\text { very broad band due to vibrations of hydroxyl groups }(-\mathrm{OH}) \text { of water physically adsorbed in the } \\
\text { compounds. } \\
\text { sharp band due to stretching vibration of } \mathrm{OH} \text { group of } \mathrm{Ca}(\mathrm{OH})_{2} .\end{array}$ \\
\hline \multirow{2400}{\longrightarrow}{$\mathrm{H}-\mathrm{OH}$ bending vibration of water molecules. } \\
\hline
\end{tabular}




\begin{tabular}{|l|l|}
\hline$\sim 1420$ & $\begin{array}{l}\text { broad band due to stretching vibration of } \mathrm{CO}_{3} \text { group of } \mathrm{CaCO}_{3} \text { ( possible impurities present in the } \\
\mathrm{Ca}(\mathrm{OH})_{2} \text { used in binders preparation). }\end{array}$ \\
\hline 1200 to 950 & asymmetric stretching vibrations of $\mathrm{T}-\mathrm{O}-\mathrm{T}$ bonds of $\mathrm{SiO}_{4}$ and $\mathrm{AlO}_{4}$ tetrahedral units. \\
\hline$\sim 891$ & T-O bending vibrations of T-OH group. \\
\hline$\sim 874$ & sharp band due to bending vibration $\mathrm{CO}_{3}$ group of $\mathrm{CaCO}_{3}$. \\
\hline$\sim 715$ & binding vibrations of $\mathrm{T}-\mathrm{O}-\mathrm{T}$ bonds of $\mathrm{SiO}_{4}$ e $\mathrm{AlO}_{4}$ tetrahedral units. \\
\hline
\end{tabular}

Note: letter $\mathrm{T}$ represents tetrahedrally coordinated $\mathrm{Si}$ or $\mathrm{Al}$ atoms.

\subsection{XRD Analysis}

Products of $w F C C / C a(O H)_{2}$ alkali-activated reactions were also assessed by XRD analysis. Fig. 6 shows the XRD diffractograms obtained with wFCC catalyst as well as selected XRD diffractograms obtained with $\mathrm{AA}-\mathrm{wFCC} / \mathrm{Ca}(\mathrm{OH})_{2}$ pastes namely, with the 75wFCC_25CH and 60wFCC_40CH pastes.

The XRD diffractogram obtained with wFCC catalyst reveals that its main crystalline phase is a zeolite with a faujasite-type structure (PDF\# 73-2313).

The XRD diffractograms obtained with the $75 \mathrm{wFCC} \_25 \mathrm{CH}$ and $60 \mathrm{wFCC} \_40 \mathrm{CH}$ pastes reveal:

- the absence of the faujasite phase indicating the rapid and total dissolution of the crystalline structure of the waste catalyst used as precursor, giving rise to the formation both new amorphous and crystalline phases. This result is in good agreement with the FTIR results (section 3.3) and with other studies carried out using waste FCC catalysts provided by other refineries worldwide [20, 21]. However, typically alkali activation of other aluminosilicate precursors neither dissolves totally their crystalline phases into amorphous phases nor leads to the formation of new major crystalline phases [5];

- the occurrence of a shift in the amorphous halo from $2 \theta$ values around $22^{\circ}$ in the wFCC catalyst diffractogram to $2 \theta$ higher values of $25-35^{\circ}$ in the AA-pastes diffractograms - suggest the presence of new amorphous aluminosilicate phases. These amorphous phases are also typically formed in geopolymeric binders [21, 29]. Therefore, in line with FTIR spectroscopy results, the XRD analysis also corroborates the occurrence of geopolymerization;

- AA-reaction is associated to the consumption of $\mathrm{Ca}(\mathrm{OH})_{2}$ so that after 7 reaction days this compound is not detected even in the paste with highest initial incorporation of $\mathrm{Ca}(\mathrm{OH})_{2}, 60 \mathrm{wFCC} \_40 \mathrm{CH}$. This result indicates that excessive amount of lime has not been added in the binder blends preparation;

- the crystalline phases present are: calcium hydroxide $\left(\mathrm{Ca}(\mathrm{OH})_{2}\right.$, PDF\# 84 1263), calcium carbonate $\left(\mathrm{CaCO}_{3}\right.$, PDF\# 01 0837), calcium and sodium aluminosilicate (C/N-A-S-H, PDF\# 86 0183), hydrated sodium aluminosilicate (N-A-S-H, PDF\# 38-0241), hydrated calcium aluminosilicate (C-A-S-H, PDF\# 77-1713); and Nahcolite $\left(\mathrm{NaHCO}_{3}, \mathrm{PDF} \# 74\right.$ 1203);
- $\quad$ the presence of the $\mathrm{CaCO}_{3}$ phase may be due to the samples carbonation or to the presence of impurities in raw materials, such as $\mathrm{Ca}(\mathrm{OH})_{2}$; the formation of calcium and sodium aluminosilicate have been also observed during alkali-activation of metakaolin [11, 16]; and the formation of Nahcolite have been also observed during alkali-activation of fly-ashes [14, 15].

Fig. 6 shows that there is an acceleration in the AA reaction rate with the increase of the $\mathrm{FCC} / \mathrm{Ca}(\mathrm{OH})_{2}$ ratio in the initial blend. Thus, for instance, the alkali-activation of $\mathrm{wFCC} / \mathrm{Ca}(\mathrm{OH})_{2}=60 / 40$ paste already presents, at first day of reaction, the crystalline phases $\mathrm{C} / \mathrm{N}-\mathrm{A}-\mathrm{S}-\mathrm{H}$ and $\mathrm{N}-\mathrm{A}-\mathrm{S}-\mathrm{H}$ whereas the AA $w F C C / C a(O H)_{2}=75 / 25$ paste only presents these phases after 2 days reaction.

Moreover, the XRD diffractograms analysis suggest that $\mathrm{Ca}(\mathrm{OH})_{2}$ content in the initial binder composition influences the AA reaction mechanism because the products $\mathrm{C}-\mathrm{A}-\mathrm{S}-\mathrm{H}$ and $\mathrm{NaHCO}_{3}$ only occur in the ${ }_{6} \mathrm{FCC} / \mathrm{Ca}(\mathrm{OH})_{2}=60 / 40$ paste.

The aforementioned changes in the reaction kinetics and in reaction mechanism should determine the differences in the mechanical properties of the corresponding AA-mortars materials (Fig. 4).

The prosecution of this research study is needed in order to deepen the understanding of the reactional mechanism and its correlation with the mechanical properties. Within this scope, the AA-wFCC catalyst $/ \mathrm{Ca}(\mathrm{OH})_{2}$ binders is currently under an extensive characterization, for longer reaction times (90 days), both at macro and microscale. 


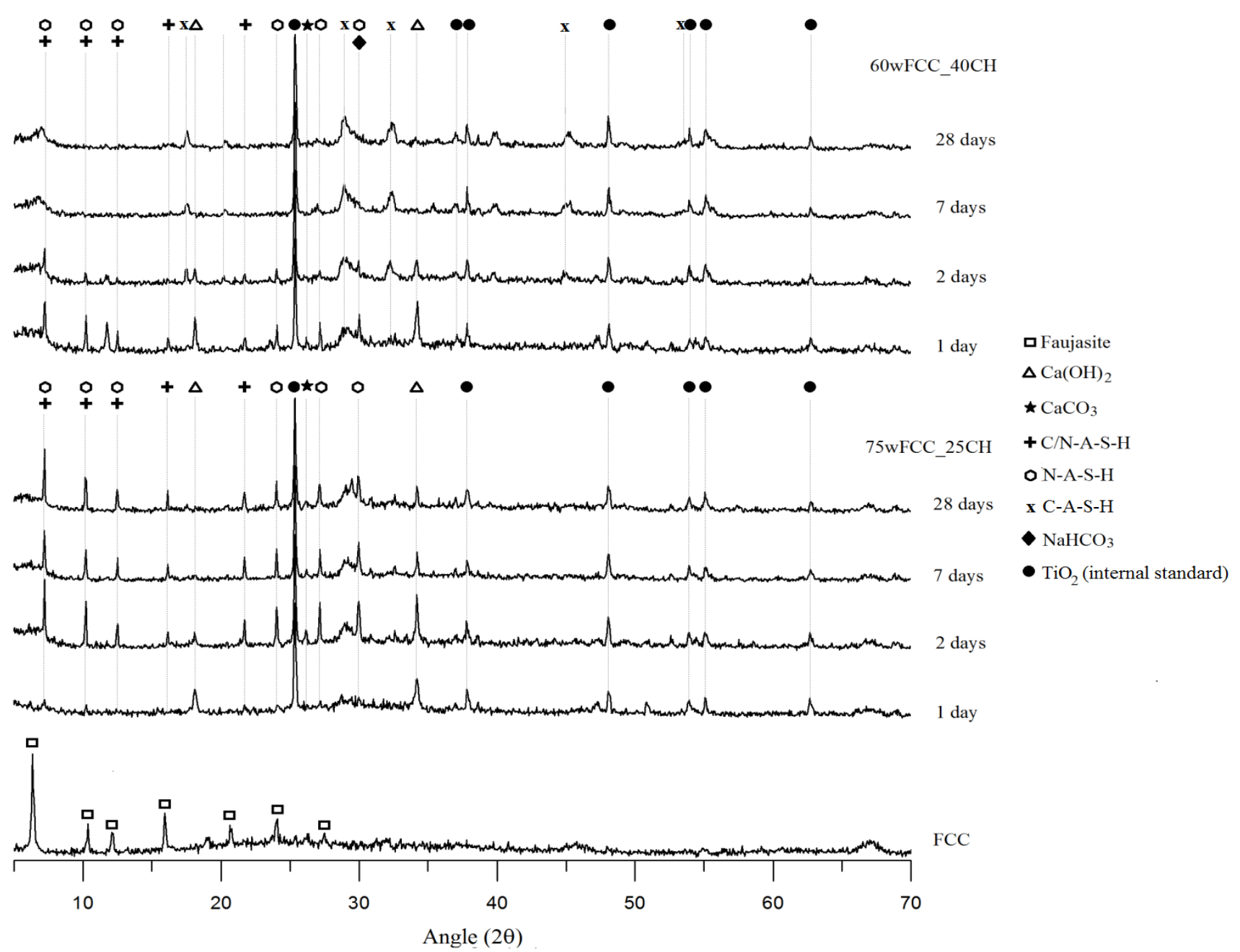

Fig. 6: XRD diffractograms of wFCC catalyst as well as of $75 w F C C \_25 \mathrm{CH}$ and $60 w F C C \_40 \mathrm{CH}$ pastes at 1,2, 7 and 28 days of alkali-activation reaction.

\section{CONCLUSIONS}

This study was conducted to assess the potential of producing alkali activated binders using the $\mathrm{wFCC}$ catalyst generated by PETROGAL, the Portuguese oil refining company. The following main conclusions can be drawn from the experimental results presented in this paper:

- $\mathrm{Ca}(\mathrm{OH})_{2}$ is required in the binder composition to obtain hardened AA mortars made from wFCC catalyst provided by PETROGAL;

- $\quad \mathrm{Ca}(\mathrm{OH})_{2}$ content in the binder significantly affects the mortars compressive strengths namely, as the $\mathrm{AA}$ reaction proceeds the maximum strength value shifts towards lower content of $\mathrm{Ca}(\mathrm{OH})_{2}$;

- mortars with incorporation of $\mathrm{Ca}(\mathrm{OH})_{2}$ up to $30 \%$ exhibit an increase in strength development during the first 28 days of reaction whereas for $35 \%$ and $40 \%$ of incorporation the mortars exhibit a strength reduction after a given reaction time;

- microstructural analysis of $\mathrm{AA}-\mathrm{wFCC} / \mathrm{Ca}(\mathrm{OH})_{2}$ pastes, both by FTIR and XRD methods, showed a rapid and total dissolution of the crystalline structure component of the waste catalyst as well as the formation of crystalline and amorphous geopolymer products;

- the reaction kinetics and the mechanism of geopolymerization seems to depend on the ${ }_{w F C C} / \mathrm{Ca}(\mathrm{OH})_{2}$ ratio used in the binder preparation. As such, there are differences in the phases present in the hardened AA-binders responsible for their different compressive strengths behaviour.

Major finding of this study is that the activation of wFCC catalyst for use in the production of alkali activated binders is feasible. Research results do contribute for both a better understanding of the wFCC catalyst geopolymerization mechanism and to support future industrial applications.

\section{ACKNOWLEDGEMENTS}

The authors acknowledge the support of Fundação para a Ciência e Tecnologia (FCT) and company Petróleos de Portugal - PETROGAL, S.A. through project funding PTDC/ECM/113115/2009 and Prof. Teresa Duarte (IST, Lisbon) for access to the XRD facility (CONCREEQ/670/2001). 


\section{REFERENCES}

[1]. Davidovits, J., Geopolymer Chemistry and Applications, Saint-Quentin, France, Institut Géopolymère, 2011.

[2]. P. Duxson, A. F.-J., J. L. Provis, G. C. Lukey, A. Palomo, J. S. J. van Deventer, "Geopolymer technology: the current state of the art", Journal of Materials Science, vol. 42, 2007, Page(s): 2917-2933.

[3]. C. Shi, A. Fernández-Jiménez, A. Palomo, "New cements for the 21st century: the pursuit of an alternative to Portland cement", Cement Concret Research, vol. 41, 2011, Page(s): 750-763.

[4]. K. Komnitsas, D. Zaharaki, "Geopolymerisation A review and prospects for the minerals industry", Minerals Engineering, vol. 20, 2007, Page(s): 1261-1277.

[5]. H. Xu, J. S. J. van Deventer, "The geopolymerisation of alumino-silicate minerals", International Journal of Mineral Processing, vol. 59, 2000, Page(s): 247-266.

[6]. H. Mingyu, Z. Xiaomin, L. Fumei, "Alkali-activated fly ash-based geopolymers with zeolite or bentonite as additives", Cement \& Concrete Composites, vol. 31, 2009, Page(s): 762-768.

[7]. J. Wang, C. Zhang, J. Xu, P. Qu, Y. Zhou, H. Han, “The Effect of Alkali on Compressive of Metakaolin Based Geopolymeric Cement", Advanced Materials Research, vol. 554-556, 2012, Page(s): 327-330.

[8]. S. Alonso, A. Palomo, "Alkaline activation of metakaolin and calcium hydroxide mixtures: influence of temperature, activator concentration and solids ratio", Materials Letters, vol. 47, 2001, Page(s): 55-62.

[9]. C. K. Yip, G. C. Lukey, S. J. S. Deventer, "The coexistence of geopolymeric gel and calcium silicate hydrate gel at the early stage of alkaline activation", Cement and Concrete Research, vol. 35, 2005, Page(s): 1688-1697.

[10]. M. Asadi, R. Naghizadeh, A. Nemati, K. Arzani, R. Nassiri, "Synthesis and microstructural properties of a geopolymer cement with high silica materials", Journal of Ceramic Processing Research, vol. 13, 2012, Page(s): 425428.

[11]. S. A. Bernal, J. L. Provis, V. Rose, R. M. Gutiérrez, "High-resolution X-ray diffraction and fluorescence microscopy characterization of alkali-activated slagmetakaolin binders", Journal of the American Ceramic Society, vol. 96, 2013, Page(s): 1951-1957.

[12]. C. D. Budh, N. R. Warhade, "Effect of molarity on compressive strength of geopolymer mortar", International Journal of Civil Engineering Research, vol. 5, 2014, Page(s): 83-86.

[13]. J. W. Phair; J. S. J. Deventer, J. D. Smith, "Mechanism of polysialation in the incorporation of zirconia into fly-ash based geopolymers", Industrial \& Engineering Chemistry Research, vol. 39, 2000, Page(s): 2925-2934.

[14]. A. S. Vargas, D. C. C. Dal Molin, A. C. F. Vilela, F. J. Silva, B. Pavão, H. Veit, "The effects of Na2O/SiO2 molar ratio, curing temperature and age on compressive strength, morphology and microstructure of alkali-activated fly ashbased geopolymers", Cement \& Concrete Composites, vol. 33, 2011, Page(s): 653-660.

[15]. A. Fernández-Jiménez, A. Palomo, "Composition and microstructure of alkali activated fly ash binder: Effect of the activator", Cement and Concrete Research, vol. 35, 2005, Page(s): 1984-1992.

[16]. S. A. Bernal, R. M. Gutierrez, J. L. Provis, V. Rose, "Effect of silicate modulus and metakaolin incorporation on the carbonation of alkali silicate-activated slags", Cement and Concrete Research, vol. 40, 2010, Page(s): 898-907.

[17]. P. Torgal, J. P. Castro-Gomes, S. Jalali, "Investigação sobre a evolução da resistência em argamassas geopoliméricas à base de lamas residuais das minas da Panasqueira", Engenharia Civil UM, vol. 32, 2008, Page(s): 5-1.

[18]. L. Reig, M.M. Tashima, M.V. Borrachero, J. Monzó, C.R. Cheeseman, J. Payá, Properties and microstructure of alkali-activated red clay brick waste, Construction and Building Materials, vol. 43, 2013, Page(s): 98-106.

[19]. M. M. Tashima, J.L. Akasaki, V.N. Castaldelli, L. Soriano, J. Monzó, J. Payá, M.V. Borrachero, "New geopolymeric binder based on fluid catalytic cracking catalyst residue (FCC)", Materials Letters, vol. 80, 2012, Page(s): 50-52.

[20]. E. D. Rodríguez, S. A. Bernal, J. L. Provis, J. D. Gehman, J. M. Monzó, J. Payá, M. V. Borrachero, "Geopolymers based on spent catalyst residue from a fluid cracking (FCC) process", Fuel, vol. 109, 2013, Page(s): 493-502.

[21]. M. M. Tashima, J.L. Akasaki, J. L. P. Melges, L. Soriano, J. Monzó, J. Payá, M. V. Borrachero, "Alkali activated materials based on fluid catalytic cracking catalyst residue (FCC): Influence of $\mathrm{SiO} 2 / \mathrm{Na} 2 \mathrm{O}$ and $\mathrm{H} 2 \mathrm{O} / \mathrm{FCC}$ ratio on mechanical strength and microstructure", Fuel, vol. 108, 2013, Page(s): 833-839.

[22]. C. Costa, P. Marques, "Low-carbon cement with waste oil-cracking catalyst incorporation", Cement Industry Technical Conference, 2012 IEEE-IAS/PCA 53RD Cement, Austin, USA.

[23]. C. Costa, M. S. Ribeiro, N. Brito, "Concrete repair mortar made of a waste from oil refining industry", Proceedings of the International Sustainable Building Conference Graz 2013. A. H. Passer, K; Maydl, P. Graz University of Technology, Graz, Austria, Verlag der Technischen Universität Graz, Page(s): 1455-1462.

[24]. E. A. Ortega, C. Cheeseman, J. Knight, M. Loizidou, "Properties of alkali-activated clinoptilolite", Cement and Concrete Research, vol. 30, 2000, Page(s): 1641-1646.

[25]. J. Paya, J. Monzo, M. V. Borrachero, S. Velázquez, M. Bonilla, "Determination of the pozzolanic activity of fluid catalytic cracking residue. Thermogravimetric analysis studies on FC3R-lime pastes", Cement and Concrete Research, vol. 33, 2003, Page(s): 1085-1091.

[26]. I. Sperberga, M. Rundans, G. Sedmale, A. Cimmers, V. Seglins, "Suitability of illite based clays of Latvia for chemical and thermal activation", Material Science and Applied Chemistry, vol. 29, 2013, Page(s): 46-50.

[27]. A. Hawa, D. Tonnayopas, W. Prachasaree, P. Taneerananon, "Investigating the effects of oil palm ash in metakaolin based geopolymer", Ceramics - Silikáty, vol. 57, 2013, Page(s): 319-327.

[28]. A. Grill, "Porous pSiCOH ultralow-k dielectrics for chip interconnects prepared by PECVD", Annual Review of Materials Research, vol. 39, 2009, Page(s): 49-69. 
[29]. J. L. Provis, G. C. Lukey, J. S. J. van Deventer, "Do geopolymers actually contain nanocrystalline zeolites? A reexamination of existing results", Chemistry of Materials, vol. 17, 2005, Page(s): 3075-3085.

\section{BIOGRAPHIES}

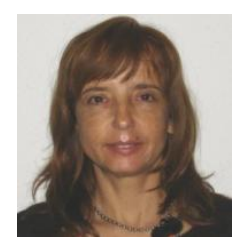

Carla Costa received the $\mathrm{PhD}$ degree in Chemical Engineering from Instituto Superior Técnico (IST), Technical University of Lisbon, Portugal. Her current research interests are centered on the study and development of innovative solutions to hydraulic binders.

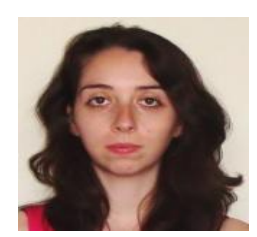

Cátia Ferreira has received her masters in Biological Engineering from University of Minho, Portugal. Her interests include study and development of alkali-activated binder materials.

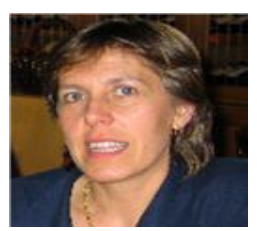

M. Filipa Ribeiro has received her graduation in $\mathrm{PhD}$ in Chemical Engineering from Instituto Superior Técnico (IST), Portugal. Her research interests are in the field of heterogeneous catalysis: acid and bifunctional catalysis with zeolites; environmental catalysis; synthesis and postsynthesis modification of microporous materials.

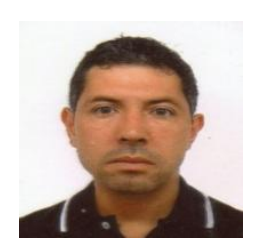

Auguste Fernandes has received his $\mathrm{PhD}$ degree from Paul Sabatier University, Toulouse, France. He is currently postdoctoral fellow from CRERG group, IST Lisbon. His research interests include hydrothermal synthesis of micro- and mesoporous materials and heterogeneous acid catalysts, their chemical modification and characterization. 